\title{
"Alleviating World Suffering The Challenge of Negative Quality of Life", by Ronald Anderson (Ed.) Cham, Springer. ISBN 978-3-319-51391-1
}

\author{
Patsy Kraeger ${ }^{1}$
}

Published online: 26 January 2021

(C) The International Society for Quality-of-Life Studies (ISQOLS) and Springer Nature B.V. 2021

Anderson (2014) explains in his initial work exploring human suffering and quality of life, he learned, after digesting much research on human suffering, there is a diversity of opinions in this subject. Suffering is "severe distress that damages one's body, mind or interpersonal relationships but also damages one's self identity. ... [I]t encompasses not only physical hurts' but mental and emotional trauma and destruction of dignity of individuals, social groups and even societies" (Anderson 2015 3-12 cited in Anderson and Otten 2017:4). With Alleviating World Suffering The Challenge of Negative Quality of Life, Anderson and Otten (2017) and co-authors in this edited volume explore deeply differing approaches and resolutions for alleviating negative quality of life as a result of complex problems causing world suffering. Approaches to suffering alleviation or reduction are defined and explored in 27 chapters in this book through theoretical, empirical, critical inquiry and case study research.

The approaches to alleviating world suffering are interdisciplinary and comprehensive allowing researchers, academics, students as well policy makers to better understand the complexity of world suffering, examine solutions and take action for community change or build on the research in this volume. Anderson and Otten's (2015, 2017) definition is the starting place for his opening chapter on frameworks for suffering alleviation which are enhanced from the interdisciplinary quality of life approach examining additional alleviation of suffering. The book is divided into five sections, which examine historical and current contexts for world suffering causes and alleviation approaches.

Part one, Humanitarian and Social Perspectives on Suffering Alleviation, provides the contextual framing of the book. The five chapters in this section guide readers in their exploration of the underlying causes and world beliefs on suffering. Anderson suggests six frameworks including an ethical and moral lens for suffering alleviation. Rothbart and Poder consider the construct of humiliation as a daily form of suffering

Patsy Kraeger

pkraeger@georgiasouthern.edu

1 Georgia Southern University, Statesboro, Georgia 
and its effects of intergroup and societal relations and a call for adopting norms of dignity. Chouliaraki addresses the ethics of solidarity and the need for deeper communication in the international NGO arena to focus suffering alleviation on a common agenda rather than salvation of the pitiable. How might this occur in any context, the shift in thinking and action? Wilkinson (2017:68) calls for "more complete pathways out of social suffering" by exploring new roles for humanitarian research in the social sciences from morals, values and interpersonal relationships to further debate in the fields of sociology and anthropology. Cooper importantly looks to synergies and dysergies of individual human suffering allowing for self actualization across and within people" (2017:82).

These frameworks in part one recognize that while suffering is individual and subjective there are larger societal and group impacts that must be considered in order to alleviate human suffering. As such, part two of the book, Quality of Life (QOL), Caring and Suffering Alleviation, examines how such suffering might be reduced from theoretical and applied chapters balancing well-being against ill-being to models of care to reduce pain and suffering. Sirgy approaches alleviation by discussing indicators for well-being but recognizing negative indicators of ill-being. Opposite indicators allow readers to assess and measure the extent of suffering and alleviation. Bhuiyan presents a case study focusing on behavioral health and "mental suffering" and alleviation using national indices for measurement of change in three villages in Bangladesh to further research and policy change. Mahoney and Harder in caregiving focus on empathic suffering for others and the costs of caring to reframe the discussion of suffering as experience by individuals and on behalf of others. Moving from the empathic to the altruistic, Kwon and Firat examine the cultural lens for the development "altruistic personal identities as they relate to social identities ... investigate the implications of altruistic value obligations like benevolence and caring for the community" (2017: 147). They suggest that this work will lead to contextual differences with future work studying suffering in order to shed light on the "altruistic self and values..." (2017:162). Neimeyer shifts the focus here to a critical piece on the use of group therapy as to alleviate grief in order to make sense and meaning from grief. This chapter discusses best practices for grief alleviation with a focus on restorative storytelling and sense making. Rosenblatt presents a thought-provoking chapter on why people may not care to alleviate suffering from acts of omission such as the tacit not knowing what to do to acts of commission, acute indifference or intentional lack of caring. With the understanding of the variations in caring, Rosenblatt posits that "perhaps those who are able and willing to act might ideally be given as much support for their efforts as possible and as much help at being as good as they can be in what they do (2017: 193).

Part three considers three specific areas for institutional and systemic suffering alleviation: Improving Global Development, Healthcare and Poverty Reduction which builds on how people might step up for change. The five chapters in this section examine larger systemic change to structural changes needed for suffering alleviation. Hickel invites us to think philosophically about structural, development and economic goals while debating "good and evil" as the basis for assessing suffering both in international development and economic development. Chapters 13 to 15, together explore the plights of the people living on the margins where structurally there is limited human dignity afforded to population growth and justice around reproductive rights. 
Violent Societal Conflict, Human Rights and Justice make up the discussion in part four and again we see the call for large scale systemic changes to alleviate suffering that occurs in the present and past suffering where trauma has been passed down through generations. Oliner in Chapter 17 and Adam et al., in chapter 18 uniquely examine past suffering and the impacts on survivors from the Holocaust to the Indian School system. Kennedy (ch. 19), Féron (ch.20) and Boyle and Svec (ch. 21) recognize the need for coordinated approaches to alleviate large-scale suffering from victims of rape contracting HIV/AIDS to reproductive rights to maternal and child health are among the main topics in these chapters. Institutional reforms from law to reconsidering development approach supplements frameworks discussed in part one of this volume. Chapters 17, 18, 22 and 23 present useful case studies of conflict related suffering and processes for alleviation if not resolution from the suffering. Muller, Sinclair and Woolford show us how technology can be used through visualization processes to heal trauma and suffering. The role of visualization is one that allows for the sufferer to make sense of the suffering and help to rescue that suffering. While this tool may alleviate both individual and community lived experience of suffering objectively the tool can bring about systemic changes to suffering. Both traditional and state-of-the-art technological solutions can successfully be employed to shift thinking from current and past violent conflicts for current and hereditary trauma sufferers.

Finally, part five focuses on the future. How can we prevent suffering in the future? Cases in education, economic development and the environment display how capacity to avoid suffering in the first pace can occur through intentional actions. In education for example, Karraker explores how students in a higher education situation can alleviate suffering in the homeless population. At first we see awareness is key for change. That said, the emphasis is creating a social justice and civic engagement component to the curriculum that 1 allows students to act for change rather than discuss change, here it was the case of a homeless population but the model would translate to other issues as well. Hagoel examines cancer suffering from the perspective of the search for meaning and purpose recognizing the work of Viktor Frankl (1985) and the connection between meaning and well-being. Kocaoğlu and Phillips despite the market economy as the sole model for economic development and discuss the caring economy. "Caring economics represents a way to help alleviate suffering, by expanding emphasis from beyond economic self-interest to one that is more inclusive of compassionate actions"(2017: 429). As Hagoel is on the quest for purpose and meaning with cancer, Kocaoğlu and Phillips search for firms hat can create both profit and societal benefit by refuting classical economic theories and advocating for a values based theory for the economy. Solidarity is central to this values based approach. Finally, Anderson concludes the volume by exploring proactive approaches to climate change preventing extinction to an examine of climate related catastrophes to calling for a re-framing of projects and solutions for those who have minimal resources and may be on the margins including adhering to the Sustainable Development Goals, new housing patterns like in the ecovillages to improved climate action and humanitarian relief.

All three chapters examining future preventative measures imagine a world changed though large-scale systemic change in education, the economy and the environment. There are programs in colleges and universities globally incorporating civic engagement to produce a next generation of citizen and servant leaders who are aware and engaged in change efforts to directly or indirectly alleviate suffering. 
In conclusion this book is a valuable addition to the research on human and global suffering. Importantly Alleviating World Suffering The Challenge of Negative Quality of Life presents concepts, theories, empirical studies and case studies that examine not only the "why" and "how" of suffering but the path to alleviate suffering from an interdisciplinary approach. The challenge of this book for the reader is where to begin given the complexity of the volume and the topics covered. Readers ideally should start with Anderson's chapter one and Sirgy's chapter six to define and frame suffering and alleviation and to think about measurements for success. The five subpart categorical headings direct readers to specific areas of interest in parts two thorough five beyond the initial framing in part one.

Anderson and Otten (2017) in the introduction suggests that the volume is ripe for researchers, academics and students. As a whole the volume is a resource for researchers, academic, instructors and students in quality of life as an institutional reference and for research, teaching and learning. After reading the volume and the comments of several authors, I would suggest that this work is also especially important for policy makers, government agency and bureau heads/leadership as well as community advocates and leaders seeking large-scale systems change to complex social problems.

Today, as the world is suffering in a global pandemic, the calculus of humans suffering from the novel coronavirus, Covid 19 both individually and collectively has multiplied as people become sick, lose their jobs, businesses are shuttered, schools close, people are isolated increasingly and loneliness and social disconnection is on the rise, communities and economies suffer. The 27 uniquely important chapters in this book consider the multitude of complex problems that we, human kind, are facing today and in the future from the current global pandemic and its aftermath. Alleviating World Suffering The Challenge of Negative Quality of Life offers theoretical approaches, empirical data, cases as examples, indicators on which to assess progress to address the types of human suffering we as a globe are enduring in and beyond the current global pandemic holistically. It is a tool as well as a resource to understand the past, make sense of the present and plan for the future. The book benchmarks suffering alleviation and in that regard makes this book a landmark in the field.

\section{References}

Anderson, R. E. (2014). Conceptualizing human pain and suffering. In Human suffering and quality of life (pp. 1-16). Springer.

Anderson, R. E. (Ed.). (2015). World suffering and quality of life (Vol. 56). Springer.

Anderson, R. E., \& Otten, (2017). Alleviating world suffering. Springer.

Frankl, V. E. (1985). Man's search for meaning. Simon and Schuster.

Publisher's Note Springer Nature remains neutral with regard to jurisdictional claims in published maps and institutional affiliations. 